\title{
A Critical Overview of Interleukin 32 in Leishmaniases
}

\author{
Fátima Ribeiro-Dias* and lara Barreto Neves Oliveira \\ Laboratório de Imunidade Natural, Instituto de Patologia Tropical e Saúde Pública, Universidade Federal de Goiás, \\ Goiânia, Brazil
}

Interleukin-32 (IL-32) has several immune regulatory properties, which have driven its investigation in the context of various diseases. IL-32 expression is reported to be induced in the lesions of patients with American tegumentary leishmaniasis (ATL) by the New World Leishmania spp. that are responsible for causing ATL and visceral leishmaniasis (VL). IL32 expression may elevate the inflammatory process through the induction of proinflammatory cytokines and also via mechanisms directed to kill the parasites. The genetic variants of IL-32 might be associated with the resistance or susceptibility to ATL, while different isoforms of IL-32 could be associated with distinct $T$ helper lymphocyte profiles. IL-32 also determines the transcriptional profile in the bone marrow progenitor cells to mediate the trained immunity induced by $\beta$-glucan and $\mathrm{BCG}$, thereby contributing to the resistance against Leishmania. IL-32 $\gamma$ is essential for

OPEN ACCESS

Edited by:

Dario S. Zamboni,

University of São Paulo, Brazil

Reviewed by:

Som G. Nanjappa,

University of Illinois at Urbana-

Champaign, United States

*Correspondence:

Fátima Ribeiro-Dias fdias@ufg.br

Specialty section:

This article was submitted to

Parasite Immunology,

a section of the journal

Frontiers in Immunology

Received: 05 January 2022

Accepted: 11 February 2022

Published: 03 March 2022

Citation:

Ribeiro-Dias F and Oliveira I B N

(2022) A Critical Overview of Interleukin 32 in Leishmaniases.

Front. Immunol. 13:849340. doi: 10.3389/fimmu.2022.849340 the vitamin D-dependent microbicidal pathway for parasite control. In this context, the present review report briefly discusses the data retrieved from the studies conducted on IL-32 in leishmaniasis in humans and mice to highlight the current challenges to understanding the role of IL-32 in leishmaniasis.

Keywords: IL-32, Leishmania, tegumentary leishmaniasis, visceral leishmaniasis, trained immunity, genetic, vitamin D

\section{INTRODUCTION}

Interleukin 32 (IL-32) (1), which was previously known as the Natural Killer (NK) cell transcript 4 (NK4), is a cytokine secreted by both immune and non-immune cells. It was previously recognized as a pro-inflammatory cytokine. However, the existence of different isoforms of IL-32 has revealed that besides its pro- or anti-inflammatory properties, IL-32 also possesses regulatory properties (2, $3)$. The role of IL-32 has been, so far, investigated in several inflammatory and infectious diseases (4-8), including different leishmaniases (9-15).

Leishmaniases refer to a group of diseases that are caused by the Leishmania protozoa, which comprises various species with different geographic distributions across the world. These different species may be associated with diverse clinical forms of leishmaniasis, the most frequently detected ones among which are cutaneous (CL) and mucosal (ML) leishmaniases, also referred to as tegumentary leishmaniasis, and visceral leishmaniasis (VL) (16). In leishmaniasis, the disease outcomes depend on several factors, including different mammal reservoirs, vectors, parasite species, and host status. In regard to the host status, the immune responses are responsible for parasite control and also immunopathogenesis. In this context, the role of IL-32 was investigated in 
infection with Leishmania sp., which indicated IL-32 as a crucial player in the immune responses against this parasite.

In the present review, the studies on IL-32 in leishmaniases are discussed briefly, with a particular focus on the current challenges encountered in this field, including the high number of IL-32 isoforms with different properties and interactions, the lack of a known IL-32 receptor to date, and the difficulties associated with murine models.

\section{BIOLOGY OF IL-32}

IL-32 is considered a pro-inflammatory cytokine, despite there being no sequence homology to any of the other cytokine families (1). While IL-32 is mainly reported as a human/ primate-specific gene (17), its expression has been detected in other mammals as well, although not in rodents $(1,18)$. The biological activity of IL-32 is conserved across different species. Although rodents do not exhibit IL-32 expression, their cells are able to respond to IL-32 and subsequently produce several proinflammatory cytokines $(1,19)$.

IL-32 is predominantly intracellular, although it may also be secreted depending on the isoform, cell type, and context. While the exact localization of IL-32 inside a cell has not been determined so far, its co-localization with lysosomes (10), endoplasmic reticulum (20), Golgi apparatus (21), and mitochondria are reported (22). The IL32 gene contains eight exons, and different isoforms are generated through alternative mRNA splicing. To date, IL-32 $\alpha$, IL-32 $\beta$, IL-32 $\gamma$, IL-32 $\delta$, IL-32 $\theta$, IL-32 $\epsilon$, IL-32 $\zeta$, IL-32 $\eta$, and IL-32s isoforms have been identified. IL-32 $\gamma$ is considered the most potent isoform, capable of inducing higher tumor necrosis factor (TNF-a) production compared to the other isoforms (23). The interaction between these isoforms results in the functional diversity of IL-32 (24). For instance, IL-32 $\delta$ interacts with IL-32 $\beta$ and inhibits IL-10 induction through this isoform (25).

IL-32 is produced by immune cells (such as macrophages, monocytes (26), NK cells (27), and T lymphocytes) (28), as well as by non-immune cells (epithelial (29), endothelial (20, 30), mesenchymal stromal cells (31), and fibroblasts) (32). Certain tumor cell lines express IL-32 constitutively (33-35). Proinflammatory cytokines such as (TNF- $\alpha$; 19), IL-12 (1), IL-18 (4), and IL- $1 \beta$ (36) induce IL-32 production. IL-32 is also expressed in viral (37-39), bacterial (40,41), fungal (42), and protozoan infections (9). Pathogen-associated molecular patterns, such as lipopolysaccharide (LPS), muramyl dipeptide (MDP), RNA analog Poly (I:C), and oxidative stress, also induce IL-32 $(21,26,43,44)$. In turn, IL-32 induces TNF- $\alpha$, macrophage inflammatory protein 2 , IL-8, and IL- $1 \beta$, via NF- $\kappa \mathrm{B}, \mathrm{AP}-1$, and p38-MAPK signaling pathways, in monocytes/macrophages ( 1 , 36), synovial fibroblasts $(4,45)$, and $\mathrm{T}$ cells $(1,19,46)$. In epithelial cells, IL-32 $\gamma$ acts synergistically with the NOD1/2 receptors and induces IL- $1 \beta$ secretion (47). In fibroblast-like synoviocytes, IL-32 $\gamma$ upregulates TLR2 and NOD2, thereby inducing IL- $1 \beta$ in response to the cell wall components of Streptococcus pyogenes (48). Moreover, IL-32 $\gamma$ promotes the differentiation of monocytes into macrophages or dendritic cells (DC) $(49,50)$.

Proteinase 3 (PR3)-proteinase-activated receptor 2 (PR2) axis is the main IL-32 receptor candidate. PR3 was reportedly activated by IL-32 $\gamma$, leading to the activation of the G proteincoupled receptor PR2, which then induced a cytokine response via Ras-Raf and TRIF $(51,52)$. PR3 exhibits affinity to IL-32 $\alpha$ (51) and IL-32 $\gamma(53)$ and is expressed mainly in neutrophils. The tripeptide motif Arg-Gly-Asp (RGD) present in the IL-32 isoforms occurs in different accessibility forms (54) that allow interaction with the integrin present on the cell surface, adhesion regulation, migration (55), apoptosis, and angiogenesis (56). IL$32 \alpha$, IL-32 $\beta$, and [to a lesser extent] IL-32 $\gamma$ bind to the extracellular domain of integrin $\alpha \mathrm{V} \beta 3$ (54). The binding between RGD and integrin activates the intracellular kinases, such as focal adhesion kinase (FAK) (57), and may activate the $\beta 3$-p38MAPK pathway (32). IL-32 also interacts directly with the focal adhesion protein paxillin (54).

Each IL-32 isoform may interact with a specific protein kinase $\mathrm{C}(\mathrm{PKC})$ to modulate gene expression. IL-32 $\alpha$ interacts with PKC $\epsilon$ and STAT3 (58). IL-32 $\beta$ interacts with PKC $\epsilon$ and $\mathrm{C} / \mathrm{EBP} \alpha$, leading to IL-10 upregulation (59). IL-32 $\beta$ also binds to the proto-oncogene $\mathrm{Src}$ in breast cancer cells to induce glycolysis (27). IL-32 $\theta$ interacts with $\mathrm{PKC} \delta$, decreasing CCL5 production via STAT3 phosphorylation (60). IL-32 $\theta$ inhibits the PKC- $\delta$ mediated pathways responsible for TNF- $\alpha$ and IL- $1 \beta$ production $(1,61)$.

IL-32 $\gamma$ appeared to protect against in vivo Mycobacterium tuberculosis (MTB) infection in humans and IL-32 transgenic mice $(6,41)$. However, this effect declined at the later stages of infection, when the mRNA of IL-32 $\gamma$ was spliced into IL-32 $\beta$ mRNA, which increased the levels of IL-10-expressing macrophages or DCs (41). For its protective effects, besides apoptosis induction (62), IL-32 $\gamma$ also induces the expression of 25-hydroxyvitamin D3 1-alpha-hydroxylase (CYP27B1), which converts inactive vitamin $\mathrm{D}(25 \mathrm{D})$ into bioactive 1,25 -dihydroxy vitamin $\mathrm{D} 3$, which then binds to VDR (vitamin $\mathrm{D}$ receptor) and increases the production of antimicrobial peptides cathelicidin and $\beta$-defensin (6). IL-32 $\gamma$ is reported to protect against other mycobacterial infections as well $(26,63)$.

In human $I L-32$ transgenic murine models, IL $32 \beta$ reportedly increased the inflammation and worsened sepsis (17), besides inducing neuroinflammation in the brain (64). The proinflammatory activity of IL32 $\beta$ was also observed in arthritis and colitis mouse models (19). In contrast, IL-32 $\beta$ exhibited antiinflammatory effects by reducing arthritis (65) and tumor growth in IL32 $\beta$-transgenic mice (64) or in vivo arthritis model (45) as well as colitis (66) and protection against tuberculosis in IL-32 $\gamma$ transgenic mouse models (41).

In HIV infection, IL-32 $\gamma$ induced viral production in latentlyinfected $\mathrm{CD}^{+} \mathrm{T}$ cells (67). The IL32 single-nucleotide polymorphism (SNP) rs4349147 has been associated with HIV susceptibility (68). In a study, the $G$ allele-bearing cells that exhibited a shift to IL-32 isoforms other than IL-32 $\alpha$, such as IL$32 \gamma$ or IL-32 $\beta$, became cells prone to HIV infection (7). In hepatitis virus (HCV and HBV) infections, IL-32 appears to 
contribute to inflammation and fibrosis by inducing proinflammatory cytokines (69), apoptosis (70), B7-H6 expression on hepatocytes (71), and interferon IFN- $\Lambda 1$ (72). Intracellular IL-32 inhibits $\mathrm{HBV}$ replication and downregulates the transcription factors essential for HBV via the ERK1/2 pathway (73).

\section{IL-32 IN DIFFERENT LEISHMANIASES}

\section{American Tegumentary Leishmaniasis (ATL)}

IL-32 is highly expressed in lesions in both CL and ML patients (9). The IL-32 protein and IL-32 $\gamma$ mRNA detected in mucosal lesions were reportedly associated with TNF- $\alpha$ expression, indicating a role of IL-32 in the immunopathogenesis of ATL. IL-32 has been detected in the mononuclear cells of the inflammatory infiltrate and also in non-immune cells such as epithelial and endothelial cells. Amastigote forms of $L$. braziliensis induced IL-32 $\gamma$ mRNA in PBMCs from healthy individuals within $24 \mathrm{~h}$ of incubation (9). Therefore, while IL$32 \gamma$ is produced immediately upon the initial interactions of immune cells with parasites, it may also be detected during chronic inflammation. In addition, IL-32 was highly detected in skin lesions of patients infected with L. amazonensis (12).
Upon IL-32 $\gamma$ silencing or overexpression in the human monocytic THP-1 cell line, early expression of IL-32 $\gamma$ mRNA was confirmed for L. braziliensis and L. amazonensis, and it was dependent on TNF- $\alpha$. Moreover, the expressions of TNF- $\alpha$ mRNA and IL- 8 mRNA and protein induced by each Leishmania sp. were dependent on IL-32 $\gamma$. However, TNF- $\alpha$ was produced at similar levels upon exposure to L. amazonensis or L. braziliensis in an IL-32 $\gamma$-independent manner. Only $L$. braziliensis could induce IL- $1 \beta$ production independent of IL-32 $\gamma$. The IL-1 receptor antagonist (IL-1Ra) mRNA and protein levels and IL-10 mRNA levels were higher after exposure to L. amazonensis compared to L. braziliensis, and only $L$. amazonensis-induced IL-1Ra was affected by IL-32 $\gamma$ expression (10). These findings suggested that the effect of IL$32 \gamma$ expression on cytokine production differs with the Leishmania species. In the absence of IL-32 $\gamma$, the infection index increased, which was attributed to the decreased levels of iNOS/NO (nitric oxide) and antimicrobial peptides ( $\beta$-defensin2 and cathelicidin). Reactive oxygen intermediates (ROS) and antimicrobial peptides are reported to kill Leishmania $(74,75)$. Accordingly, IL-32 $\gamma$ overexpression led to better parasite control together with increased production of microbicidal molecules (Figure 1A) (10). Therefore, IL-32 $\gamma$ expression is crucial for parasite control against both the Leishmania species.

Dos Santos et al. (14) demonstrated that both L. amazonensis and L. braziliensis could induce IL-32 $\gamma$ mRNA in the PBMCs
A

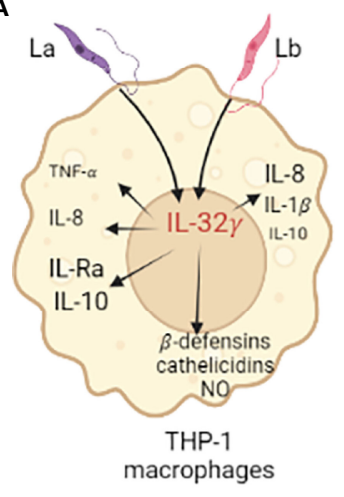

B

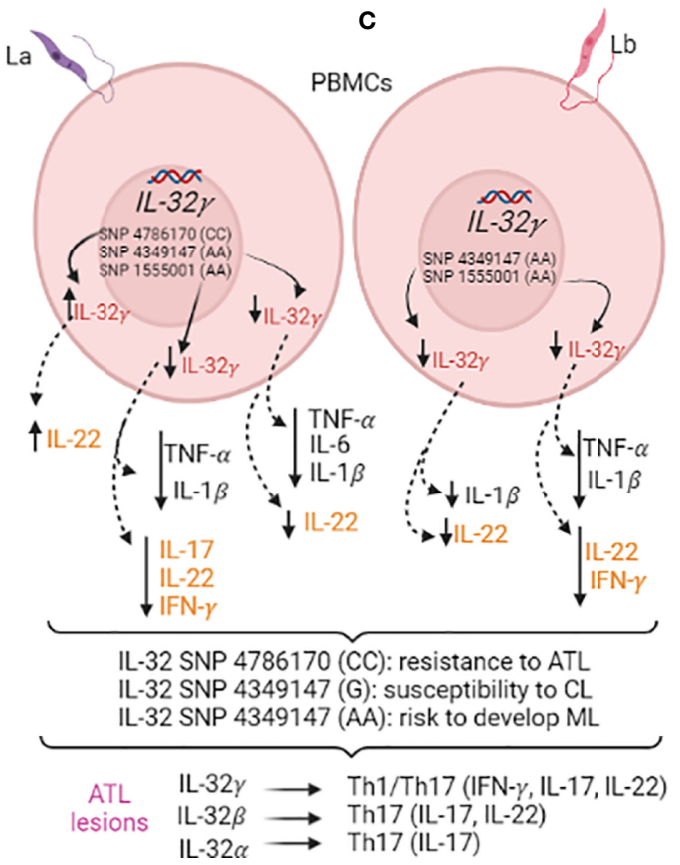

D

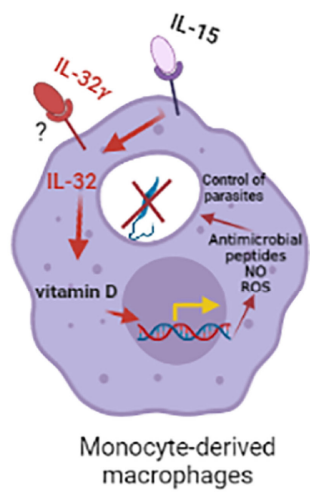

FIGURE 1 | Interleukin-32 in Leishmania infections. (A) Human macrophages derived from the monocyte cell line THP-1 were infected with L. amazonensis (La) or L. braziliensis (Lb) (MOI 5:1) after IL-32 $\gamma$ silencing (siRNA) or overexpression (plasmid) for evaluation of cytokine and antimicrobial molecules. (B, C) PBMCs from healthy individuals genotyped for three IL32 variants were exposed to La (B) or Lb (C) promastigote lysates for cytokine evaluation (innate - TNF- $\alpha$, IL-1 $\beta$, IL-6/24 h; acquired immunity: IL-22, IL-17, IFN- $\gamma$ /seven days) and association with ATL and its clinical outcome; expression of cytokines and different IL-32 isoforms were evaluated in lesions of ATL patients and positive correlations were obtained. (D) Human monocyte-derived macrophages were infected with Lb after priming with recombinant cytokines - IL-15 (inducer of IL-32) and/or IL-32 $\gamma$ to evaluate vitamin D-dependent microbicidal pathway and NO and ROS production. 
from healthy individuals within $24 \mathrm{~h}$ of incubation, while IL-32 $\beta$ and IL-32 $\alpha$ mRNA were detected only after seven days. This suggested that isoforms other than IL-32 $\gamma$ could be produced during in vivo infection, which could differentially modulate the immune responses. The search for the innate receptors responsible for IL-32 induction revealed that toll-like receptor 4 (TLR4), NOD2, and Dectin-1 recognized Leishmania molecules for IL-32 induction (14). Lipophosphoglycan (LPG) from Leishmania activates TLR4 and NOD-like receptors (NLRP3) to increase cytokine production (76-78). Therefore, LPG is a suitable candidate parasite-derived molecule for inducing IL-32 production during Leishmania infection.

The major challenge in the study of the mechanisms and biological activities of IL-32 in infectious diseases is the lack of a known receptor for IL-32. Strategies other than those aiming at the blocking/inhibition of cytokine receptor/signaling are required to investigate the role of IL-32 in leishmaniases. In this context, a genomic functional study allows identifying the genetic variants of IL-32 (79) capable of regulating its production and influencing the development and disease outcome in tegumentary leishmaniasis. Three IL32 variants already evaluated in other diseases $(7,80-82)$ were investigated in ATL. A Brazilian cohort of ATL patients and healthy individuals were evaluated for IL32 SNP rs4786370 (promoter region), which is associated with protection against ATL. When PBMCs from healthy individuals (200FG cohort; 79; http://www. humanfunctionalgenomics.org/site/) were exposed to $L$. amazonensis lysate, the CC genotype of IL32 rs478670 exhibited increased IL-32 $\gamma$ mRNA expression. Nonetheless, the production of innate (IL-1 $\beta$, TNF- $\alpha$, IL-6) or acquired (IFN $\gamma$, IL-17) immunity cytokines remained unaltered. However, IL-22 levels increased in the CC genotype individuals (14).

While intronic IL32 SNP rs1555001 and enhancer IL32 SNP rs4349147 were not associated with ATL susceptibility or resistance, a decrease was observed in IL-32 $\gamma$ mRNA, TNF- $\alpha$, IL-1 $\beta$, IL-22, and IFN- $\gamma$ expressions in $L$. amazonensis-or $L$. braziliensis-exposed PBMCs with the AA genotype of rs 1555001 SNP. Moreover, L. amazonensis exposure led to decreased IL-17 induction. In the AA genotype of IL32 SNP rs4349147, exposure to both Leishmania species led to decreased IL-32 $\gamma$, IL-1 $\beta$, and IL-22 levels, while TNF- $\alpha$ and IL-6 levels decreased only upon $L$. amazonenis exposure. The SNPs rs4786370 and rs1555001 were not associated with clinical outcomes; the IL32 SNP rs4349147 allele $\mathrm{G}$ was present at high frequency in CL patients, while allele A was overrepresented in ML patients (14). These findings, together with the observations that these cytokines are highly expressed in ATL lesions and IL-32 isoforms are associated with innate and acquired cytokines, suggest that increased IL- $32 \gamma$ and IL-22 levels protect against ATL, while decreased levels of these cytokines represent a risk for ML. In murine models, IL-22 is considered irrelevant to parasite control $(83,84)$, although it does facilitate healing of the lesions, thereby protecting against tissue damage (84). The three IL32 SNPs evaluated in Dos Santos et al. (14) affected the expression of IL-22, which is strongly associated with IL-32 $\gamma$ in ATL lesions. Notably, while IL-32 $\gamma$ was associated with IFN- $\gamma$ and IL-17 (Th1/Th17 profile), IL-32 $\beta$ was associated with IL-22 and IL-17, and IL-32 $\alpha$ with IL-17 (Th17 profile) (14) (Figures 1B, C). Therefore, the isoforms could be determinant to the acquired immune responses against Leishmania.

The role of IL-32 in the clinical outcome of diseases has been evaluated in human IL-32 transgenic mice. Choi et al. (66) used the mouse strain C57BL/6 to develop IL-32 $\gamma$ transgenic mice (IL$32 \gamma \mathrm{Tg}$ ), in which the chicken $\beta$-actin promoter drives IL-32 $\gamma$ expression in all tissues. In this mouse model, IL-32 $\gamma$ promoted parasite control and lesion healing after infection with $L$. braziliensis, and was associated with the increased production of Th1 cytokines (12). While IL-32 $\gamma$ did not contribute to the healing of lesions caused by L. amazonensis, it decreased parasite dissemination from the footpad to the liver or spleen (12). This mouse model was also used to evaluate the role of IL-32 in trained immunity as an alternative mechanism to enhance protection against Leishmania. In the study, $\beta$-glucan was first used for training the human monocytes (85), which induced IL$32 \gamma$ mRNA expression and IL-32 production while also enhancing the control of L. braziliensis. These results were mechanistically explained by an increase in the expression of antimicrobial peptides cathelicidin and $\beta$-defensin-2. The stratification of healthy individuals according to their IL32 SNP rs4786370 genotype (200FG cohort; 79 ) revealed that the CC genotype expressed higher levels of IL-32 $\gamma$, IL- $1 \beta$, IL- 6 , and TNF- $\alpha$ in $\beta$-glucan-trained macrophages compared to the TT genotype. The presence of this IL32 variant was also associated with a decreased infection index. These findings, together with the genomic functional data, suggested that $\beta$-glucan induces IL32 and IL-1 $\beta$, which then mediate trained immunity and enhance protection against $L$. braziliensis infection (85).

In IL-32 $\gamma \mathrm{Tg}$ mice, $\beta$-glucan training increased resistance against $L$. braziliensis infection, which was mechanistically explained by an increased expression of the genes associated with cell cycle, myeloid lineages, and regulatory enzymes of the glycolytic pathway in bone marrow cells. Similar results were reported for human BCG-vaccinated volunteers genotyped for IL32 SNP rs4786370, in which the bone marrow myeloid progenitor cells with CC genotype presented an association of IL-32 expression with increased metabolic gene expression, besides inflammation (86). BCG reportedly induces IL-32 (40, 87), while BCG-trained monocytes exhibit enhanced capacity to kill $L$. braziliensis, $L$. amazonensis, and $L$. infantum through

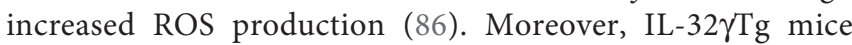
trained with BCG exhibit resistance to $L$. braziliensis and $L$. infantum, and control of $L$. amazonensis dissemination. This was associated with increased inflammation (87). Data indicate that IL-32 serves as a determinant of gene expression profile at the level of bone marrow progenitors by mediating the trained immunity induced by $\beta$-glucan or BCG and conferring protection against leishmaniasis. Dos Santos et al. reported a review on BCG in leishmaniasis (88).

One of the microbicidal pathways driven by IL- $32 \gamma$ is the vitamin $\mathrm{D}$-dependent production of antimicrobial peptides. $L$. braziliensis infection in human monocyte-derived macrophages was reportedly best controlled when the culture medium contained IL- $32 \gamma$ and a sufficient amount of vitamin D 
(Figure 1D) (15). However, this pathway appears important in the control of various microorganisms in human macrophages as the IL-32-vitamin D axis is also crucial for controlling the growth of Paracoccidioides brasiliensis, a fungus that causes paracoccidioidomycosis (42).

Although IL-32 $\gamma \mathrm{Tg}$ mice have been useful in studying the role of IL-32 in leishmaniases, the differences between humans and mice render these unsuitable as an optimal model. For instance, the vitamin $\mathrm{D}$ pathway in mice lacks the induction of $\beta$-defensin2 and cathelicidin (89), consequently limiting the use of this IL32 -dependent pathway in IL-32 $\gamma \mathrm{Tg}$ mouse in analyses. Moreover, mice and humans differ in the NO levels generated after Leishmania infection and their relevance in parasite control $(15,90,91)$. Therefore, the effects of IL-32 on microbicidal pathways could differ between humans and mice.

\section{Visceral Leishmaniasis (VL)}

Leishmania infantum promastigotes may induce high levels of IL-32 $\gamma$ expression and IL-32 production and low levels of IL-32 $\beta$ in human PBMCs. In IL-32 $\gamma \mathrm{Tg}$ mice, IL-32 $\gamma$ expression was reportedly increased in the liver and spleen, which ultimately reduced the parasite burden and increased granuloma formation in the liver, compared to wild-type mice. The protection was associated with Th1 and Th17 cells, which produced cytokines that contributed to NO production (13). IL-32 $\gamma$ also enhanced the protective role of neutrophils in VL. IL-32 $\gamma$ increased the number of neutrophils in mouse spleen and liver after $L$. infantum infection via IL-17-dependent cell recruitment. Recombinant IL-32 $\gamma$ increased ROS production in both mouse and human neutrophils (92). Together, data suggest a crucial role of the IL-32 $\gamma$-Th17-neutrophil axis in the control of experimental VL. As stated above, IL-32 appears to mediate the BCG-trained immunity, which confers protection against $L$. infantum to human monocytes/macrophages and IL-32 $\gamma$ Tg mice (87). However, data on the role of IL-32 in the course of human VL deserve investigation.

\section{CONCLUSION}

Studies have demonstrated that IL-32 plays a crucial role in leishmaniases. However, studies attempting to unravel the role of

\section{REFERENCES}

1. Kim S, Han S, Azam T, Yoon D, Dinarello C. Interleukin-32a Cytokine and Inducer of TNF $\alpha$. Immunity (2005) 22:131-42. doi: 10.1016/S1074-7613(04) 00380-2

2. Ribeiro-Dias F, Saar Gomes R, de Lima Silva LL, dos Santos JC, Joosten LAB. Interleukin 32: A Novel Player in the Control of Infectious Diseases. J Leukoc Biol (2017) 101:39-52. doi: 10.1189/jlb.4RU0416-175RR

3. dos Santos JC, Damen MSMA, Joosten LAB, Ribeiro-Dias F. Interleukin-32: An Endogenous Danger Signal or Master Regulator of Intracellular Pathogen Infections-Focus on Leishmaniases. Semin Immunol (2018) 38:15-23. doi: 10.1016/j.smim.2018.02.010

4. Joosten LAB, Netea MG, Kim S-H, Yoon D-Y, Oppers-Walgreen B, Radstake TRD, et al. IL-32, a Proinflammatory Cytokine in Rheumatoid Arthritis. Proc Natl Acad Sci (2006) 103:3298-303. doi: 10.1073/pnas.0511233103
IL-32 in leishmaniases and other diseases encounter certain major challenges, including the high number of IL-32 isoforms, each with distinct biological properties, lack of a recognized IL-32 receptor, the large sample size required for genetic studies, few individuals with IL32 variants available for functional studies, and the differences in the IL-32 $\gamma$-mediated microbicidal pathways between humans and mice. Future studies should investigate the presence of other IL-32 isoforms, in vivo, during microbial infection and attempt to identify IL-32 receptors to unravel the mechanisms through which IL-32 modulates immune responses during infection with different Leishmania species.

\section{AUTHOR CONTRIBUTIONS}

FR-D was responsible for designing, organizing and, revising the manuscript. Both authors contributed to the literature review, analyzes the studies, writing of the manuscript, and approved the submission.

\section{FUNDING}

Coordenação de Aperfeiçoamento de Pessoal de Nível Superior Brazil (CAPES) - Finance Code 001, by FAPEG - grant n. 465771/2014-9 - INCT/IPH - National Institute of Science and Technology for strategies in host-pathogen interaction, Brazil. FAPEG - PRONEM grant n. 201710267000516.

\section{ACKNOWLEDGMENTS}

The authors thank all the supports; we are member of National Institute of Science and Technology for Strategies in HostPathogen Interactions (INCT-IPH) and PRONEM 07/2016, supported by Fundação de Amparo à Pesquisa do Estado de Goiás (FAPEG); IO is fellow of the Coordenação de Aperfeiçoamento de Pessoal de Nível Superior, Brazil (CAPES)/FAPEG - Finance Code 001. FR-D is CNPq's researcher fellow. We thank Sci-Edit for editing our paper, it helped us in publishing our paper.

5. Shioya M, Nishida A, Yagi Y, Ogawa A, Tsujikawa T, Kim-Mitsuyama S, et al Epithelial Overexpression of Interleukin-32 $\alpha$ in Inflammatory Bowel Disease IL-32 $\alpha$ and IBD. Clin Exp Immunol (2007) 149:480-6. doi: 10.1111/j.13652249.2007.03439.x

6. Montoya D, Inkeles MS, Liu PT, Realegeno S, B. Teles RM, Vaidya P, et al. IL32 is a Molecular Marker of a Host Defense Network in Human Tuberculosis Sci Transl Med (2014) 6(250):250ra114. doi: 10.1126/scitranslmed.3009546

7. Palstra R-J, de Crignis E, Röling MD, van Staveren T, Kan TW, van Ijcken W, et al. Allele-Specific Long-Distance Regulation Dictates IL-32 Isoform Switching and Mediates Susceptibility to HIV-1. Sci Adv (2018) 4:e1701729. doi: $10.1126 /$ sciadv.1701729

8. Braga YLL, Neto JRC, Costa AWF, Silva MVT, Silva MV, Celes MRN, et al. Interleukin-32 $\gamma$ in the Control of Acute Experimental Chagas Disease. $J$ Immunol Res editado por Syed Sameer Aga (2022) 2022:1-9. doi: 10.1155/ 2022/7070301 
9. Galdino H, Maldaner AE, Pessoni LL, Soriani FM, Pereira LI de A, Pinto SA, et al. Interleukin $32 \gamma$ (IL-32 $\gamma$ ) is Highly Expressed in Cutaneous and Mucosal Lesions of American Tegumentary Leishmaniasis Patients: Association With Tumor Necrosis Factor (TNF) and IL-10. BMC Infect Dis (2014) 14:249. doi: 10.1186/1471-2334-14-249

10. dos Santos JC, Heinhuis B, Gomes RS, Damen MSMA, Real F, Mortara RA, et al. Cytokines and Microbicidal Molecules Regulated by IL-32 in THP-1Derived Human Macrophages Infected With New World Leishmania Species. PloS Negl Trop Dis (2017) 11:e0005413. doi: 10.1371/journal.pntd.0005413

11. dos Santos JC, Damen MSMA, Oosting M, de Jong DJ, Heinhuis B, Gomes RS, et al. The NOD2 Receptor Is Crucial for Immune Responses Towards New World Leishmania Species. Sci Rep (2017) 7:15219. doi: 10.1038/s41598-01715412-7

12. Gomes RS, Silva MVT, dos Santos JC, de Lima Silva LL, Batista AC, Machado JR, et al. IL-32 $\gamma$ Promotes the Healing of Murine Cutaneous Lesions Caused by Leishmania braziliensis Infection in Contrast to Leishmania amazonensis. Parasites Vectors (2017) 10:336. doi: 10.1186/s13071-017-2268-4

13. Gomes RS, Silva MVT, dos Santos JC, van Linge C, Reis JM, Teixeira MM, et al. Human Interleukin-32 $\gamma$ Plays a Protective Role in an Experimental Model of Visceral Leishmaniasis in Mice. Infect Immun (2018) 86(5):e0079617. doi: 10.1128/IAI.00796-17

14. dos Santos JC, Leite Quixabeira VB, Teodoro Silva MV, Damen MSMA, Schraa K, Jaeger M, et al. Genetic Variation in Interleukin-32 Influence the Immune Response Against New World Leishmania Species and Susceptibility to American Tegumentary Leishmaniasis. PloS Negl Trop Dis (2020) 14: e0008029. doi: 10.1371/journal.pntd.0008029

15. Silva LL de L, Gomes RS, Silva MVT, Joosten LAB, Ribeiro-Dias F. IL-15 Enhances the Capacity of Primary Human Macrophages to Control Leishmania Braziliensis Infection by IL-32/Vitamin D Dependent and Independent Pathways. Parasitol Int (2020) 76:102097. doi: 10.1016/ j.parint.2020.102097

16. Goto H, Lauletta Lindoso JA. Cutaneous and Mucocutaneous Leishmaniasis. Infect Dis Clin North Am (2012) 26:293-307. doi: 10.1016/j.idc.2012.03.001

17. Kobayashi H, Huang J, Ye F, Shyr Y, Blackwell TS, Lin PC. Interleukin-32 $\beta$ Propagates Vascular Inflammation and Exacerbates Sepsis in a Mouse Model. PloS One (2010) 5:e9458. doi: 10.1371/journal.pone.0009458

18. Kim S. Interleukin-32 in Inflammatory Autoimmune Diseases. Immune Netw (2014) 14:123. doi: 10.4110/in.2014.14.3.123

19. Shoda H, Fujio K, Yamaguchi Y, Okamoto A, Sawada T, Kochi Y, et al. Interactions Between IL-32 and Tumor Necrosis Factor Alpha Contribute to the Exacerbation of Immune-Inflammatory Diseases. Arthritis Res Ther (2006) 8:R166. doi: 10.1186/ar2074

20. Kobayashi H, Lin PC. Molecular Characterization of IL-32 in Human Endothelial Cells. Cytokine (2009) 46:351-8. doi: 10.1016/j.cyto.2009.03.007

21. Zahoor M, Westhrin M, Aass KR, Moen SH, Misund K, Psonka-Antonczyk KM, et al. Hypoxia Promotes IL-32 Expression in Myeloma Cells, and High Expression is Associated With Poor Survival and Bone Loss. Blood Adv (2017) 1:2656-66. doi: 10.1182/bloodadvances.2017010801

22. Park JS, Lee S, Jeong AL, Han S, Ka HI, Lim J-S, et al. Hypoxia-Induced IL-32 $\beta$ Increases Glycolysis in Breast Cancer Cells. Cancer Lett (2015) 356:800-8. doi: 10.1016/j.canlet.2014.10.030

23. Choi J-D, Bae S-Y, Hong J-W, Azam T, Dinarello CA, Her E, et al. Identification of the Most Active Interleukin-32 Isoform. Immunology (2009) 126:535-42. doi: 10.1111/j.1365-2567.2008.02917.x

24. Kang J-W, Park YS, Kim MS, Lee DH, Bak Y, Ham SY, et al. IL-32 $\alpha$ DownRegulates $\beta 2$ Integrin (CD18) Expression by Suppressing PU.1 Expression in Myeloid Cells. Cell Signal (2014) 26:1514-22. doi: 10.1016/j.cellsig. 2014.03.027

25. Kang J-W, Park YS, Lee DH, Kim MS, Bak Y, Park SH, et al. Interleukin- $32 \delta$ Interacts With IL-32 $\beta$ and Inhibits IL-32 $\beta$-Mediated IL-10 Production. FEBS Lett (2013) 587:3776-81. doi: 10.1016/j.febslet.2013.10.019

26. Schenk M, Mahapatra S, Le P, Kim HJ, Choi AW, Brennan PJ, et al. Human NOD2 Recognizes Structurally Unique Muramyl Dipeptides From Mycobacterium Leprae. Infect Immun (2016) 84:2429-38. doi: 10.1128/ IAI.00334-16

27. Park MH, Song MJ, Cho M-C, Moon DC, Yoon DY, Han SB, et al. Interleukin-32 Enhances Cytotoxic Effect of Natural Killer Cells to Cancer Cells via Activation of Death Receptor 3: Interleukin-32 Enhances NK Cell
Cytotoxicity. Immunology (2012) 135:63-72. doi: 10.1111/j.1365-2567. 2011.03513.x

28. Goda C, Kanaji T, Kanaji S, Tanaka G, Arima K, Ohno S, et al. Involvement of IL-32 in Activation-Induced Cell Death in T Cells. Int Immunol (2006) 18:233-40. doi: 10.1093/intimm/dxh339

29. Zhang L, Che C, Lin J, Liu K, Li D-Q, Zhao G. TLR-Mediated Induction of Proinflammatory Cytokine IL-32 in Corneal Epithelium. Curr Eye Res (2013) 38:630-8. doi: 10.3109/02713683.2012.763102

30. Meyer N, Christoph J, Makrinioti H, Indermitte P, Rhyner C, Soyka M, et al. Inhibition of Angiogenesis by IL-32: Possible Role in Asthma. J Allergy Clin Immunol (2012) 129:964-973.e7. doi: 10.1016/j.jaci.2011.12.1002

31. Zhang Y-Y, Xu L, Li D-Q, Shao J-H, Chen P, Zhao H-Y, et al. IL-32 mRNA Expression of Bone Marrow Stromal Cells and Its Correlation With Cell Apoptosis in Patients With Myelodysplastic Syndrome. Zhongguo Shi Yan Xue Ye Xue Za Zhi (2016) 24:773-8. doi: 10.7534/j.issn.1009-2137. 2016.03.026

32. Wen S, Hou Y, Fu L, Xi L, Yang D, Zhao M, et al. Cancer-Associated Fibroblast (CAF)-Derived IL32 Promotes Breast Cancer Cell Invasion and Metastasis via Integrin $\beta 3-\mathrm{P} 38$ MAPK Signalling. Cancer Lett (2019) 442:320-32. doi: 10.1016/j.canlet.2018.10.015

33. Paz H, Tsoi J, Kalbasi A, Grasso CS, McBride WH, Schaue D, et al. Interleukin 32 Expression in Human Melanoma. J Transl Med (2019) 17:113. doi: 10.1186/s12967-019-1862-y

34. Plantinga TS, Costantini I, Heinhuis B, Huijbers A, Semango G, Kusters B, et al. A Promoter Polymorphism in Human Interleukin-32 Modulates its Expression and Influences the Risk and the Outcome of Epithelial CellDerived Thyroid Carcinoma. Carcinogenesis (2013) 34:1529-35. doi: 10.1093/ carcin/bgt092

35. Heinhuis B, Plantinga TS, Semango G, Küsters B, Netea MG, Dinarello CA, et al. Alternatively Spliced Isoforms of IL-32 Differentially Influence Cell Death Pathways in Cancer Cell Lines. CARCIN (2016) 37:197-205. doi: 10.1093/carcin/bgv172

36. Hong J, Bae S, Kang Y, Yoon D, Bai X, Chan ED, et al. Suppressing IL-32 in Monocytes Impairs the Induction of the Proinflammatory Cytokines TNF $\alpha$ and IL-1ß. Cytokine (2010) 49:171-6. doi: 10.1016/j.cyto.2009.10.003

37. Li W, Sun W, Liu L, Yang F, Li Y, Chen Y, et al. IL-32: A Host Proinflammatory Factor Against Influenza Viral Replication Is Upregulated by Aberrant Epigenetic Modifications During Influenza A Virus Infection. J Immunol (2010) 185:5056-65. doi: 10.4049/jimmunol.0902667

38. Lai K-Y, Chou Y-C, Lin J-H, Liu Y, Lin K-M, Doong S-L, et al. Maintenance of Epstein-Barr Virus Latent Status by a Novel Mechanism, Latent Membrane Protein 1-Induced Interleukin-32, via the Protein Kinase C $\delta$ Pathway. J Virol (2015) 89:5968-80. doi: 10.1128/JVI.00168-15

39. Lee S, Kim J-H, Kim H, Kang JW, Kim S-H, Yang Y, et al. Activation of the Interleukin-32 Pro-Inflammatory Pathway in Response to Human Papillomavirus Infection and Over-Expressionof Interleukin-32 Controls the Expression of the Humanpapillomavirus Oncogene: Feedback Mechanism of IL-32 in HPV. Immunology (2011) 132:410-20. doi: 10.1111/ j.1365-2567.2010.03377.x

40. Netea MG, Azam T, Lewis EC, Joosten LAB, Wang M, Langenberg D, et al. Mycobacterium Tuberculosis Induces Interleukin-32 Production Through a Caspase- 1/IL-18/Interferon- $\gamma$-Dependent Mechanism. PloS Med (2006) 3: e277. doi: 10.1371/journal.pmed.0030277

41. Bai X, Shang S, Henao-Tamayo M, Basaraba RJ, Ovrutsky AR, Matsuda JL, et al. Human IL-32 Expression Protects Mice Against a Hypervirulent Strain of Mycobacterium tuberculosis. Proc Natl Acad Sci USA (2015) 112:5111-6. doi: $10.1073 /$ pnas. 1424302112

42. Guimarães de Matos G, Barroso de Figueiredo AM, Diniz Gonçalves PH, Luiz de Lima Silva L, Bastista AC, Borges CL, et al. Paracoccidioides Brasiliensis Induces IL-32 and Is Controlled by IL-15/IL-32/Vitamin D Pathway In Vitro. Microb Pathogen (2021) 154:104864. doi: 10.1016/j.micpath.2021.104864

43. Kudo M, Ogawa E, Kinose D, Haruna A, Takahashi T, Tanabe N, et al. Oxidative Stress Induced Interleukin-32 mRNA Expression in Human Bronchial Epithelial Cells. Respir Res (2012) 13:19. doi: 10.1186/1465-992113-19

44. Yong HJ, Park JS, Lee Jeong A, Han S, Lee S, Ka HI, et al. Von Hippel-Lindau Regulates Interleukin-32 $\beta$ Stability in Ovarian Cancer Cells. Oncotarget (2017) 8:69833-46. doi: 10.18632/oncotarget.19311 
45. Heinhuis B, Koenders MI, van Riel PL, van de Loo FA, Dinarello CA, Netea MG, et al. Tumour Necrosis Factor Alpha-Driven IL-32 Expression in Rheumatoid Arthritis Synovial Tissue Amplifies an Inflammatory Cascade. Ann Rheum Dis (2011) 70:660-7. doi: 10.1136/ard.2010.139196

46. Nold MF, Nold-Petry CA, Pott GB, Zepp JA, Saavedra MT, Kim S-H, et al. Endogenous IL-32 Controls Cytokine and HIV-1 Production. J Immunol (2008) 181:557-65. doi: 10.4049/jimmunol.181.1.557

47. Netea MG, Azam T, Ferwerda G, Girardin SE, Walsh M, Park J-S, et al. IL-32 Synergizes With Nucleotide Oligomerization Domain (NOD) 1 and NOD2 Ligands for IL-1 and IL-6 Production Through a Caspase 1-Dependent Mechanism. Proc Natl Acad Sci (2005) 102:16309-14. doi: 10.1073/ pnas.0508237102

48. Heinhuis B, Koenders MI, van de Loo FA, van Lent PLEM, Kim S-H, Dinarello CA, et al. IL-32 and Streptococcus Pyogenes Cell Wall Fragments Synergise for IL-1-Dependent Destructive Arthritis via Upregulation of TLR2 and NOD2. Ann Rheum Dis (2010) 69:1866-72. doi: 10.1136/ ard.2009.127399

49. Netea MG, Lewis EC, Azam T, Joosten LAB, Jaekal J, Bae S-Y, et al. Interleukin-32 Induces the Differentiation of Monocytes Into MacrophageLike Cells. Proc Natl Acad Sci (2008) 105:3515-20. doi: 10.1073/ pnas.0712381105

50. Ohmatsu H, Humme D, Gonzalez J, Gulati N, Möbs M, Sterry W, et al. IL-32 Induces Indoleamine 2,3-Dioxygenase ${ }^{+} \mathrm{CD} 1 \mathrm{c}{ }^{+}$Dendritic Cells and Indoleamine 2,3-Dioxygenase ${ }^{+} \mathrm{CD} 163^{+}$Macrophages: Relevance to Mycosis Fungoides Progression. OncoImmunology (2017) 6:e1181237. doi: 10.1080/2162402X.2016.1181237

51. Novick D, Rubinstein M, Azam T, Rabinkov A, Dinarello CA, Kim S-H. Proteinase 3 is an IL-32 Binding Protein. Proc Natl Acad Sci (2006) 103:331621. doi: $10.1073 /$ pnas.0511206103

52. Nakayama M, Niki Y, Kawasaki T, Takeda Y, Ikegami H, Toyama Y, et al. IL32-PAR2 Axis is an Innate Immunity Sensor Providing Alternative Signaling for LPS-TRIF Axis. Sci Rep (2013) 3:2960. doi: 10.1038/srep02960

53. Yan H, Dong M, Liu X, Shen Q, He D, Huang X, et al. Multiple Myeloma CellDerived IL-32 $\gamma$ Increases the Immunosuppressive Function of Macrophages by Promoting Indoleamine 2,3-Dioxygenase (IDO) Expression. Cancer Lett (2019) 446:38-48. doi: 10.1016/j.canlet.2019.01.012

54. Heinhuis B, Koenders MI, van den Berg WB, Netea MG, Dinarello CA, Joosten LAB. Interleukin 32 (IL-32) Contains a Typical $\alpha$-Helix Bundle Structure That Resembles Focal Adhesion Targeting Region of Focal Adhesion Kinase-1. J Biol Chem (2012) 287:5733-43. doi: 10.1074/ jbc.M111.288290

55. Tsai C-Y, Wang C-S, Tsai M-M, Chi H-C, Cheng W-L, Tseng Y-H, et al. Interleukin-32 Increases Human Gastric Cancer Cell Invasion Associated With Tumor Progression and Metastasis. Clin Cancer Res (2014) 20:2276-88. doi: 10.1158/1078-0432.CCR-13-1221

56. Nold-Petry CA, Rudloff I, Baumer Y, Ruvo M, Marasco D, Botti P, et al. IL-32 Promotes Angiogenesis. J Immunol (2014) 192:589-602. doi: 10.4049/ jimmunol.1202802

57. Nieberler M, Reuning U, Reichart F, Notni J, Wester H-J, Schwaiger M, et al. Exploring the Role of RGD-Recognizing Integrins in Cancer. Cancers (2017) 9:116. doi: 10.3390/cancers9090116

58. Kang J-W, Park YS, Lee DH, Kim J, Kim MS, Bak Y, et al. Intracellular Interaction of Interleukin (IL)-32 $\alpha$ With Protein Kinase Ce (PKCe) and STAT3 Protein Augments IL-6 Production in THP-1 Promonocytic Cells. J Biol Chem (2012) 287:35556-64. doi: 10.1074/jbc.M112.400911

59. Kang J-W, Park YS, Kim MS, Lee DH, Bak Y, Ham SY, et al. Interleukin (IL)$32 \beta$-Mediated CCAAT/Enhancer-Binding Protein $\alpha(\mathrm{C} / \mathrm{EBP} \alpha)$ Phosphorylation by Protein Kinase $\mathrm{C} \delta$ (PKC $\delta$ ) Abrogates the Inhibitory Effect of C/Ebp $\alpha$ on IL-10 Production. J Biol Chem (2013) 288:23650-8. doi: 10.1074/jbc.M113.465575

60. Bak Y, Kang J-W, Kim MS, Park YS, Kwon T, Kim S, et al. IL-32 $\theta$ Downregulates CCL5 Expression Through its Interaction With PKC $\delta$ and STAT3. Cell Signal (2014) 26:3007-15. doi: 10.1016/j.cellsig.2014.09.015

61. Pham T-H, Bak Y, Oh J-W, Hong J, Lee S, Hong JT, et al. Inhibition of IL-13 and IL-13ro2 Expression by IL-32 $\theta$ in Human Monocytic Cells Requires Pkc $\delta$ and STAT3 Association. IJMS (2019) 20:1949. doi: 10.3390/ijms20081949

62. Bai X, Kim S-H, Azam T, McGibney MT, Huang H, Dinarello CA, et al. IL-32 Is a Host Protective Cytokine Against Mycobacterium Tuberculosis in
Differentiated THP-1 Human Macrophages. JI (2010) 184:3830-40. doi: 10.4049/jimmunol.0901913

63. Bai X, Ovrutsky AR, Kartalija M, Chmura K, Kamali A, Honda JR, et al. IL-32 Expression in the Airway Epithelial Cells of Patients With Mycobacterium Avium Complex Lung Disease. Int Immunol (2011) 23:679-91. doi: 10.1093/ intimm/dxr075

64. Yun H-M, Oh JH, Shim J-H, Ban JO, Park K-R, Kim J-H, et al. Antitumor Activity of IL-32 $\beta$ Through the Activation of Lymphocytes, and the Inactivation of NF-KB and STAT3 Signals. Cell Death Dis (2013) 4:e640-0. doi: 10.1038/cddis.2013.166

65. Park MH, Yoon D-Y, Ban JO, Kim DH, Lee DH, Song S, et al. Decreased Severity of Collagen Antibody and Lipopolysaccharide-Induced Arthritis in Human IL-32 $\beta$ Overexpressed Transgenic Mice. Oncotarget (2015) 6:3856677. doi: 10.18632/oncotarget.6160

66. Choi J, Bae S, Hong J, Ryoo S, Jhun H, Hong K, et al. Paradoxical Effects of Constitutive Human IL-32 in Transgenic Mice During Experimental Colitis. Proc Natl Acad Sci (2010) 107:21082-6. doi: 10.1073/pnas.1015418107

67. Zaidan SM, Leyre L, Bunet R, Larouche-Anctil E, Turcotte I, Sylla M, et al. Upregulation of IL-32 Isoforms in Virologically Suppressed HIV-Infected Individuals: Potential Role in Persistent Inflammation and Transcription From Stable HIV-1 Reservoirs. JAIDS J Acquir Immune Defic Syndr (2019) 82:503-13. doi: 10.1097/QAI.0000000000002185

68. Lingappa JR, Petrovski S, Kahle E, Fellay J, Shianna K, McElrath MJ, et al. Genomewide Association Study for Determinants of HIV-1 Acquisition and Viral Set Point in HIV-1 Serodiscordant Couples With Quantified Virus Exposure. PloS One (2011) 6:e28632. doi: 10.1371/journal.pone.0028632

69. Moschen AR, Fritz T, Clouston AD, Rebhan I, Bauhofer O, Barrie HD, et al. Interleukin-32: A New Proinflammatory Cytokine Involved in Hepatitis C Virus-Related Liver Inflammation and Fibrosis. Hepatology (2011) 53:181929. doi: 10.1002/hep. 24285

70. Xu Q, Pan X, Shu X, Cao H, Li X, Zhang K, et al. Increased Interleukin-32 Expression in Chronic Hepatitis B Virus-Infected Liver. J Infect (2012) 65:336-42. doi: 10.1016/j.jinf.2012.05.009

71. Zou Y, Bao J, Pan X, Lu Y, Liao S, Wang X, et al. NKP30-B7-H6 Interaction Aggravates Hepatocyte Damage Through Up-Regulation of Interleukin-32 Expression in Hepatitis B Virus-Related Acute-On-Chronic Liver Failure. PloS One (2015) 10:e0134568. doi: 10.1371/journal.pone.0134568

72. Li Y, Xie J, Xu X, Liu L, Wan Y, Liu Y, et al. Inducible Interleukin 32 (IL-32) Exerts Extensive Antiviral Function via Selective Stimulation of Interferon $\lambda 1$ (IFN- $\lambda 1$ ). J Biol Chem (2013) 288:20927-41. doi: 10.1074/jbc.M112.440115

73. Kim DH, Park E-S, Lee AR, Park S, Park YK, Ahn SH, et al. Intracellular Interleukin-32 $\gamma$ Mediates Antiviral Activity of Cytokines Against Hepatitis B Virus. Nat Commun (2018) 9:3284. doi: 10.1038/s41467-018-05782-5

74. Morato CI, da Silva IA, Borges AF, Dorta ML, Oliveira MAP, Jancar S, et al. Essential Role of Leukotriene B4 on Leishmania (viannia) braziliensis Killing by Human Macrophages. Microbes Infect (2014) 16:945-53. doi: 10.1016/ j.micinf.2014.08.015

75. El-Dirany R, Shahrour H, Dirany Z, Abdel-Sater F, Gonzalez-Gaitano G, Brandenburg K, et al. Activity of Anti-Microbial Peptides (AMPs) Against Leishmania and Other Parasites: An Overview. Biomolecules (2021) 11:984. doi: 10.3390/biom11070984

76. Nogueira PM, Assis RR, Torrecilhas AC, Saraiva EM, Pessoa NL, Campos MA, et al. Lipophosphoglycans From Leishmania amazonensis Strains Display Immunomodulatory Properties via TLR4 and Do Not Affect Sand Fly Infection. PloS Negl Trop Dis (2016) 10:e0004848. doi: 10.1371/ journal.pntd.0004848

77. Vieira T da S, Rugani JN, Nogueira PM, Torrecilhas AC, Gontijo CMF, Descoteaux A, et al. Intraspecies Polymorphisms in the Lipophosphoglycan of L. braziliensis Differentially Modulate Macrophage Activation via TLR4. Front Cell Infect Microbiol (2019) 9:240. doi: 10.3389/fcimb.2019.00240

78. de Carvalho RVH, Andrade WA, Lima-Junior DS, Dilucca M, de Oliveira CV, Wang K, et al. Leishmania Lipophosphoglycan Triggers Caspase-11 and the Non-Canonical Activation of the NLRP3 Inflammasome. Cell Rep (2019) 26:429-37.e5. doi: 10.1016/j.celrep.2018.12.047

79. Li Y, Oosting M, Smeekens SP, Jaeger M, Aguirre-Gamboa R, Le KTT, et al. A Functional Genomics Approach to Understand Variation in Cytokine Production in Humans. Cell (2016) 167:1099-110.e14. doi: 10.1016/ j.cell.2016.10.017 
80. Damen MSMA, Agca R, Holewijn S, de Graaf J, Dos Santos JC, van Riel PL, et al. IL-32 Promoter SNP rs4786370 Predisposes to Modified Lipoprotein Profiles in Patients With Rheumatoid Arthritis. Sci Rep (2017) 7:41629. doi: 10.1038/srep41629

81. Damen MSMA, Schraa K, Tweehuysen L, den Broeder AA, Netea MG, Popa CD, et al. Genetic Variant in IL-32 is Associated With the Ex Vivo Cytokine Production of Anti-TNF Treated PBMCs From Rheumatoid Arthritis Patients. Sci Rep (2018) 8:14050. doi: 10.1038/s41598-018-32485-0

82. Mazlum F, Gharesi-Fard B, Hadinedoushan H, Bakhshizadeh Ghashti Y. Association Between Interleukin-32 Gene Polymorphism and Susceptibility to Preeclampsia: Running Head: Association of IL-32 and Preeclampsia. Hypertens Pregnancy (2021) 40:218-25. doi: 10.1080/10641955.2021.1958836

83. Brosch S, Dietze-Schwonberg K, Lopez Kostka S, Lorenz B, Haak S, Becher B, et al. Disease Control in Cutaneous Leishmaniasis Is Independent of IL-22. J Invest Dermatol (2015) 135:308-11. doi: 10.1038/jid.2014.282

84. Gimblet C, Loesche MA, Carvalho L, Carvalho EM, Grice EA, Artis D, et al. IL-22 Protects Against Tissue Damage During Cutaneous Leishmaniasis. PloS One (2015) 10:e0134698. doi: 10.1371/journal.pone.0134698

85. Bekkering S, Blok BA, Joosten LAB, Riksen NP, van Crevel R, Netea MG. In Vitro Experimental Model of Trained Innate Immunity in Human Primary Monocytes. Clin Vaccine Immunol (2016) 23:926-33. doi: 10.1128/ CVI.00349-16

86. dos Santos JC, Barroso de Figueiredo AM, Teodoro Silva MV, Cirovic B, de Bree LCJ, Damen MSMA, et al. $\beta$-Glucan-Induced Trained Immunity Protects Against Leishmania braziliensis Infection: A Crucial Role for IL-32. Cell Rep (2019) 28:2659-72.e6. doi: 10.1016/j.celrep.2019.08.004

87. Silva MVT, Dos Santos JC, Figueiredo AMB de, Teufel LU, Pereira JX, Matos GG de, et al. The Role of IL-32 in Bacillus Calmette-Guérin (BCG)-Induced Trained Immunity in Infections Caused by Different Leishmania spp. Microb Pathog (2021) 158:105088. doi: 10.1016/j.micpath.2021.105088

88. dos Santos JC, Vilela Teodoro Silva M, Ribeiro-Dias F, Joosten LAB. NonSpecific Effects of BCG in Protozoal Infections: Tegumentary Leishmaniasis and Malaria. Clin Microbiol Infect (2019) 25:1479-83. doi: 10.1016/ j.cmi.2019.06.002
89. Dimitrov V, White JH. Species-Specific Regulation of Innate Immunity by Vitamin D Signaling. J Steroid Biochem Mol Biol (2016) 164:246-53. doi: 10.1016/j.jsbmb.2015.09.016

90. Liew FY, Li Y, Moss D, Parkinson C, Rogers MV, Moncada S. Resistance to Leishmania major Infection Correlates With the Induction of Nitric Oxide Synthase in Murine Macrophages. Eur J Immunol (1991) 21:3009-14. doi: 10.1002/eji.1830211216

91. Carneiro PP, Conceição J, Macedo M, Magalhães V, Carvalho EM, Bacellar O. The Role of Nitric Oxide and Reactive Oxygen Species in the Killing of Leishmania braziliensis by Monocytes From Patients With Cutaneous Leishmaniasis. PloS One (2016) 11:e0148084. doi: 10.1371/journal. pone. 0148084

92. Gomes RS, Silva MVT, Oliveira MAP, Joosten LAB, Ribeiro-Dias F. Protective Immune Response Mediated by Neutrophils in Experimental Visceral Leishmaniasis Is Enhanced by IL-32 $\gamma$. Cell Immunol (2022) 371:104449. doi: $10.1016 /$ j.cellimm.2021.104449

Conflict of Interest: The authors declare that the research was conducted in the absence of any commercial or financial relationships that could be construed as a potential conflict of interest.

Publisher's Note: All claims expressed in this article are solely those of the authors and do not necessarily represent those of their affiliated organizations, or those of the publisher, the editors and the reviewers. Any product that may be evaluated in this article, or claim that may be made by its manufacturer, is not guaranteed or endorsed by the publisher.

Copyright $\odot 2022$ Ribeiro-Dias and Oliveira. This is an open-access article distributed under the terms of the Creative Commons Attribution License (CC BY). The use, distribution or reproduction in other forums is permitted, provided the original author(s) and the copyright owner(s) are credited and that the original publication in this journal is cited, in accordance with accepted academic practice. No use, distribution or reproduction is permitted which does not comply with these terms. 